\title{
The earliest record of fossil solid-wood-borer larvae-immature beetles in 99 million-year-old Myanmar amber
}

\author{
CAROLIN HAUG ${ }^{1,2, *}$, GIDEON T. HAUG ${ }^{1}$, ANA ZIPPEL ${ }^{1}$, SERITA VAN DER WAL ${ }^{1} \&$ JOACHIM T. HAUG ${ }^{1,2}$ \\ ${ }^{1}$ Ludwig-Maximilians-Universität München, Biocenter, Großhaderner Str. 2, 82152 Planegg-Martinsried, Germany \\ ${ }^{2}$ GeoBio-Center at LMU, Richard-Wagner-Str. 10, 80333 München, Germany \\ " carolin.haug@palaeo-evo-devo.info; @ https://orcid.org/0000-0001-9208-4229 \\ "="gideon.haug@palaeo-evo-devo.info; @ https://orcid.org/0000-0002-6963-5982 \\ "=ana.zippel@palaeo-evo-devo.info; @ https://orcid.org/0000-0002-6509-4445 \\ ”=vanderwal@biologie.uni-muenchen.de @ https://orcid.org/0000-0002-7426-8777 \\ ”"joachim.haug@palaeo-evo-devo.info; @ ittps://orcid.org/0000-0001-8254-8472 \\ *Corresponding author
}

\begin{abstract}
Interactions between animals and plants represent an important driver of evolution. Especially the group Insecta has an enormous impact on plants, e.g., by consuming them. Among beetles, the larvae of different groups (Buprestidae, Cerambycidae, partly Eucnemidae) bore into wood and are therefore called wood-borer larvae or borers. While adults of these beetle groups are well known in the fossil record, there are barely any fossils of the corresponding larvae. We report here four new wood-borer larvae from Cretaceous Kachin amber (Myanmar, ca. $99 \mathrm{Ma}$ ). To compare these fossils with extant wood-borer larvae, we reconstructed the body outline and performed shape analysis via elliptic Fourier transformation and a subsequent principal component analysis. Two of the new larvae plot closely together and clearly in the same area as modern representatives of Buprestidae. As they furthermore lack legs, they are interpreted as representatives of Buprestidae. The other two new larvae possess legs and plot far apart from each other. They are more difficult to interpret; they may represent larvae of early offshoots of either Cerambycidae or Buprestidae, which still retain longer legs. These findings represent the earliest fossil record of larvae of Buprestidae and possibly of Cerambycidae known to date.
\end{abstract}

Keywords: Buprestidae, Cerambycidae, Burmese amber, Cretaceous, Kachin amber

\section{Introduction}

The interaction between plants and animals is an important driving force of evolution. This is especially true for representatives of the group Insecta, such as butterflies, beetles, or bees (e.g., Kergoat et al., 2017). On the one hand, many representatives are important pollinators of different plants, including agriculturally important ones (e.g., Potts et al., 2010; Powney et al., 2019). On the other hand, many representatives exploit different parts of plants, often causing severe damage up to the loss of entire crops (e.g., Metcalf, 1996; Evans et al., 2007; Oliveira et al., 2014). Especially some groups of beetles (Coleoptera) are known for their phytophagous behaviour, with some of these even having large economic impacts (e.g., bark beetles; Kirkendall et al., 2015 and references therein).

One such beetle group is Buprestidae. The about 15,000 formally described extant species of this group (Bellamy, 2008-2009) are collectively known as jewel beetles or metallic wood-boring beetles. As these names suggest, the adults stand out by their shiny and metallic appearance, while they otherwise look like more common beetles. Larvae, also known as flatheaded borers, resemble grubs at first sight, but differ in several aspects (e.g., Wu et al., 2017). The head is very indistinct, immersed into the wide thorax region, which lacks legs. The abdomen exhibits segmentation, but otherwise appears wormshaped (vermiform). The larvae can reach astonishing sizes of more than $100 \mathrm{~mm}$ (Bellamy \& Volkovitsh, 2005). They bore through different parts of plants, like roots, stems and leaves, fulfilling their eponymous ecological role as plant-borers. Overall, the larvae are very distinct, only very few larvae of other groups have a comparable morphology.

About 35,000 extant species of Cerambycidae, longhorn beetles, have been formally described (Svacha \& Lawrence, 2014). Adults possess the eponymous and characteristic very long antennae. The larvae, called roundheaded borers, feed on plant material, very similar to those of Buprestidae. Morphologically, certain larvae of Cerambycidae also closely resemble the latter, mainly 
differing in the transition area between thorax and abdomen: while the thorax is distinctly set off from the abdomen in larvae of Buprestidae, this transition is less pronounced in those of Cerambycidae (e.g., Wu et al., 2017).

Of Eucnemidae, false click beetles, there are about 1,500 formally described extant species (Muona, 2010). The adults are usually brown to black with often serrate or more or less comb-shaped antennae. Also here, the larvae feed on plant material as in the previous two groups, but only few can bore into wood. Such larvae of Eucnemidae also morphologically resemble those of Buprestidae, but possess outward curved mandibles (e.g., Muona, 2010).

Adult jewel beetles are well represented in the fossil record, with about 100 formally described species in the literature (Pan et al., 2011), the oldest one being of Middle Jurassic age (168-166 Ma; Alexeev, 1999). The fossil record of adult longhorn beetles is rich (see Discussion), the oldest record probably being from the Late Jurassic (ca. $150 \mathrm{Ma}$; Münster in Germar, 1839). Of false click beetles, more than 60 formally described fossil species are known (Li et al., 2021), with the oldest record from the Late Jurassic (ca. $151 \mathrm{Ma}$; Oberprieler et al., 2016).

In contrast to the fossil record of adult representatives, the fossil record of the larvae is much scarcer. Only one fossil larva of false click beetles is known (Chang et al., 2016; Early Cretaceous, $125 \mathrm{Ma}$, see Swisher et al., 1999). Some larvae of false click beetles are known to be solid-wood borers (solid-wood-boring types of Muona \& Teräväinen, 2020: fig. 6), morphologically resembling larvae of jewel beetles. Yet, most larvae of false click beetles feed on fungi in soft rotten wood and do not form galleries (Muona, 2010: 62), hence, cannot be considered solid-wood borers. The fossil described by Chang et al. (2016) is of this latter, vermiform, presumably non-solid-wood-boring type. Even older wood-boring larvae, namely of the group Micromalthidae, have been reported from Lebanese amber (Kirejtshuk \& Azar, 2008). Similar to many larvae of Eucnemidae, these larvae live in rotten, hence softer wood (e.g., Pollock \& Normark, 2002; Normark, 2013; Hörnschemeyer, 2016; Perotti et al., 2016). Few fossil larvae of longhorn beetles have been mentioned, fewer have been figured, e.g., one in Baltic amber (Eocene, ca. $38 \mathrm{Ma}$; BachofenEcht, 1949: 115, fig. 102; Gröhn, 2015: 272). Only one larval jewel beetle seems to have been figured so far (New Jersey amber, ca. 90 Ma; Grimaldi \& Engel, 2005: 381, fig. 10.36), and few cases in Baltic amber have been mentioned (Spahr, 1981 and references therein).

Here we report the first jewel beetle larvae and, possibly, longhorn beetle larvae from 99 million years old Kachin amber, Myanmar, representing the oldest records of solid wood-borer larvae. We provide a detailed comparison to their extant relatives, including a morphometric study.

\section{Material and methods}

\section{Material}

Four fossil specimens from the Palaeo-Evo-Devo Research Group Collection of Arthropods, LudwigMaximilians-Universität München are reported here (PED 0597, 0816, 0838, 1130). All are preserved in Kachin amber (Cretaceous, ca. $99 \mathrm{Ma}$ ) from the Hukawng Valley, Myanmar (Cruickshank \& Ko, 2003; Shi et al., 2012; Yu et al., 2019). The specimens were legally acquired via the internet platform ebay.com from the fossil trader burmiteminer.

One extant larval specimen of Buprestidae from the entomological collections of the Centrum für Naturkunde (CeNak) Hamburg (ZMH 62921) is included for comparison.

\section{Documentation methods}

Fossil specimens were documented on a Keyence VHX6000 digital microscope. Specimens were documented in front of different backgrounds (black and white) and different light settings (cross-polarised coaxial light, unpolarised ring light) (Haug \& Haug, 2019). Combinations with the best contrast were chosen for presentation.

All images were recorded as composite images (Haug et al., 2008; Kerp \& Bomfleur, 2011). To overcome limitations of dept of field, stacks of images with varying focus levels (frame) were recorded and fused to sharp images with the built-in software. To overcome limitations of field of view, several adjacent image details were recorded and merged to a panorama with the builtin software. To avoid overexposed or underexposed areas each frame was recorded with HDR (see Haug et al., 2013). For one close-up, a stack was recorded and processed in FIJI, generally following the method described in Haug et al. (2009).

The extant specimen was documented via macrophotography with a Canon Rebel T3i digital camera and a Canon MP-E $65 \mathrm{~mm}$ macro lens equipped with a polarisation filter. A Yongnuo YN24EX E-TTL twin flash or two Yongnuo Digital Speedlite YN560EX II flashes with polarisation filters perpendicular to that on the lens were used to illuminate the specimen. The specimen was documented in $70 \%$ ethanol; hence the cross-polarised light was necessary to reduce reflections (e.g., Haug et al., 2011). As for the fossil specimens, here adjacent image stacks were also recorded, which were subsequently fused with CombineZP and stitched with Adobe Photoshop CS3 (Haug et al., 2008).

\section{Reconstruction of body outlines}

For comparing the new fossil specimens to their extant 
counterparts, we aimed at comparing the overall body outline (for recent examples on other groups, see Haug et al., 2021a, b). The fossils, as well as many extant larvae in the literature, are not straight. Some larvae in the literature have apparently been artificially straightened (e.g., figures in Peterson, 1957, see Supplementary Table 1 and Supplementary Text 1$)$. The challenge with rather soft larvae is to not deform the larvae (e.g., to make them thinner). To provide a constant, non-deforming artificial straightening, we used the following procedure (Fig. 1; performed in Adobe Illustrator CS2):

Head and each segment were outlined with the Bezier tool on the convex side of a bent body. Each outline was drawn longer via extrapolation to allow later rotation. These lines were copied and rotated to match the concave side of the existing image. Then, head and each segment were rotated until they were straight. In this way, the natural thickness of each segment was retained; the procedure is comparable to approaches used in $3 \mathrm{D}$ modelling (e.g., Schmidt et al., 2021).

In total, 88 specimens were reconstructed, including new fossil larvae and extant larvae of Buprestidae, Cerambycidae, Schizopodidae (possible sister group to Buprestidae) and Eucnemidae (which in part resemble larvae of Buprestidae). A complete list is provided in Supplementary Table 1 (see also Supplementary Text 1).

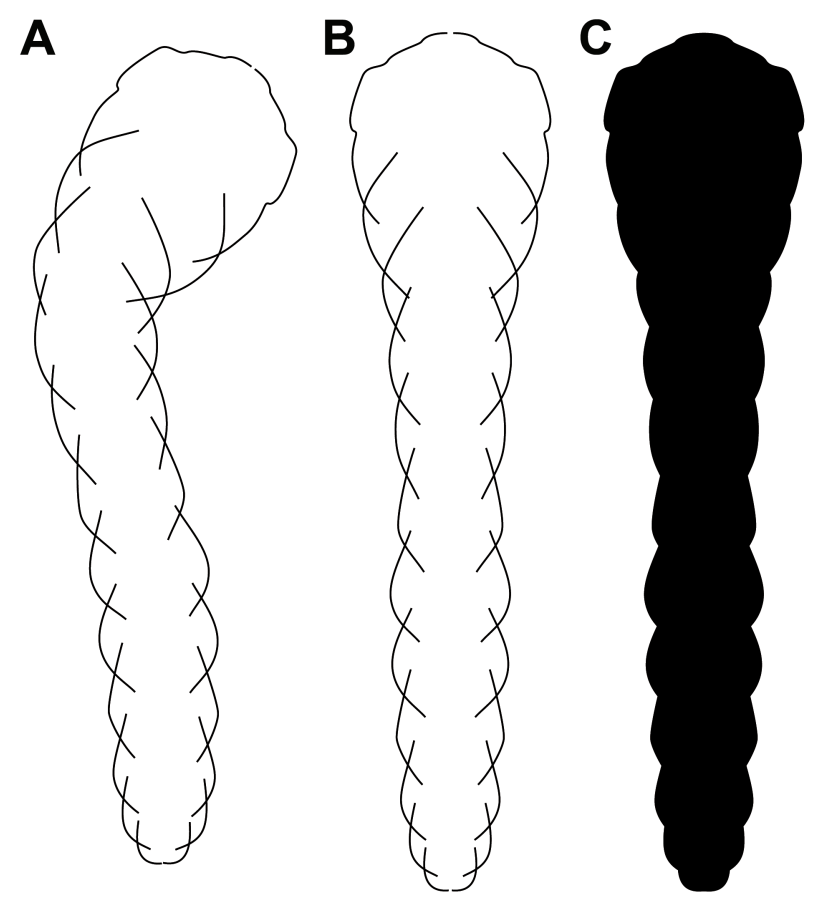

FIGURE 1. Procedure of artificial straightening of wood-borer larvae. A, Simplified re-drawing based on Volkovitsh \& Bílý (2015, their fig. 21). B, Straightened version of A. C, Filled version of $\mathbf{B}$.

\section{Shape analysis}

Reconstructed body outlines were exported as bmp-files. These files were analysed using the software package SHAPE (C) National Agricultural Research Organization of Japan). Outlines were first translated into chaincodes, aligned, and then analysed with a principal component analysis (PCA; for details, see Iwata \& Ukai, 2002; Braig et al., 2019; see Supplementary Files 1-6). The plots were prepared in OpenOffice and redrawn in Adobe Illustrator CS2.

\section{Results}

\section{General description of solid-wood-borer larvae}

The body of the larvae is very elongate and worm-like (vermiform). It is differentiated into an anterior region and a set off posterior trunk region (Fig. 2A), as the head is strongly retracted into the first trunk segment (prothorax) (Fig. 2A, B). The head bears paired antennae (often not discernible due to the retraction of head region under the prothorax; Fig. 2A, B) and mouthparts (Fig. $2 \mathrm{~A}, \mathrm{C})$. The trunk can be further differentiated into the anterior thorax and the posterior abdomen. The thorax has three segments: prothorax, mesothorax and metathorax. Thoracic segments are very prominent with a longitudinal line. The prothorax is the broadest of all the segments of the body. The longitudinal line on the prothorax is brownish in colour and prominent. The abdomen has ten apparent vermiform units, of which the anterior nine represent true segments; the abdomen units are significantly narrower than the thorax segments. Terminal end (most likely undifferentiated compound structure of abdomen segment 10 and 11) conical; oval sclerotization around anal opening. The body bears numerous small setae (Fig. 2C, D).

\section{Description of the new fossil specimens PED 0597}

Larva preserved in dorsal or ventral view (Fig. 3A, B). Total body length approximately $2.87 \mathrm{~mm}$. Head capsule trapezoid in lateral view, strongly retracted into anterior trunk (prothorax). Short antennae discernible, no details accessible. No mouth parts discernible.

Prothorax very prominent $(0.32 \mathrm{~mm}$ long and $0.47 \mathrm{~mm}$ wide), bulbous in shape from lateral view, 1.5 times wider than long; about 3 times longer than head, also about 2.25 times wider than head. Mesothorax only about 20-25\% shorter than prothorax, approximately the same in width. Metathorax shorter than prothorax, only about $50 \%$, somewhat narrower. No locomotory appendages (legs) discernible. 


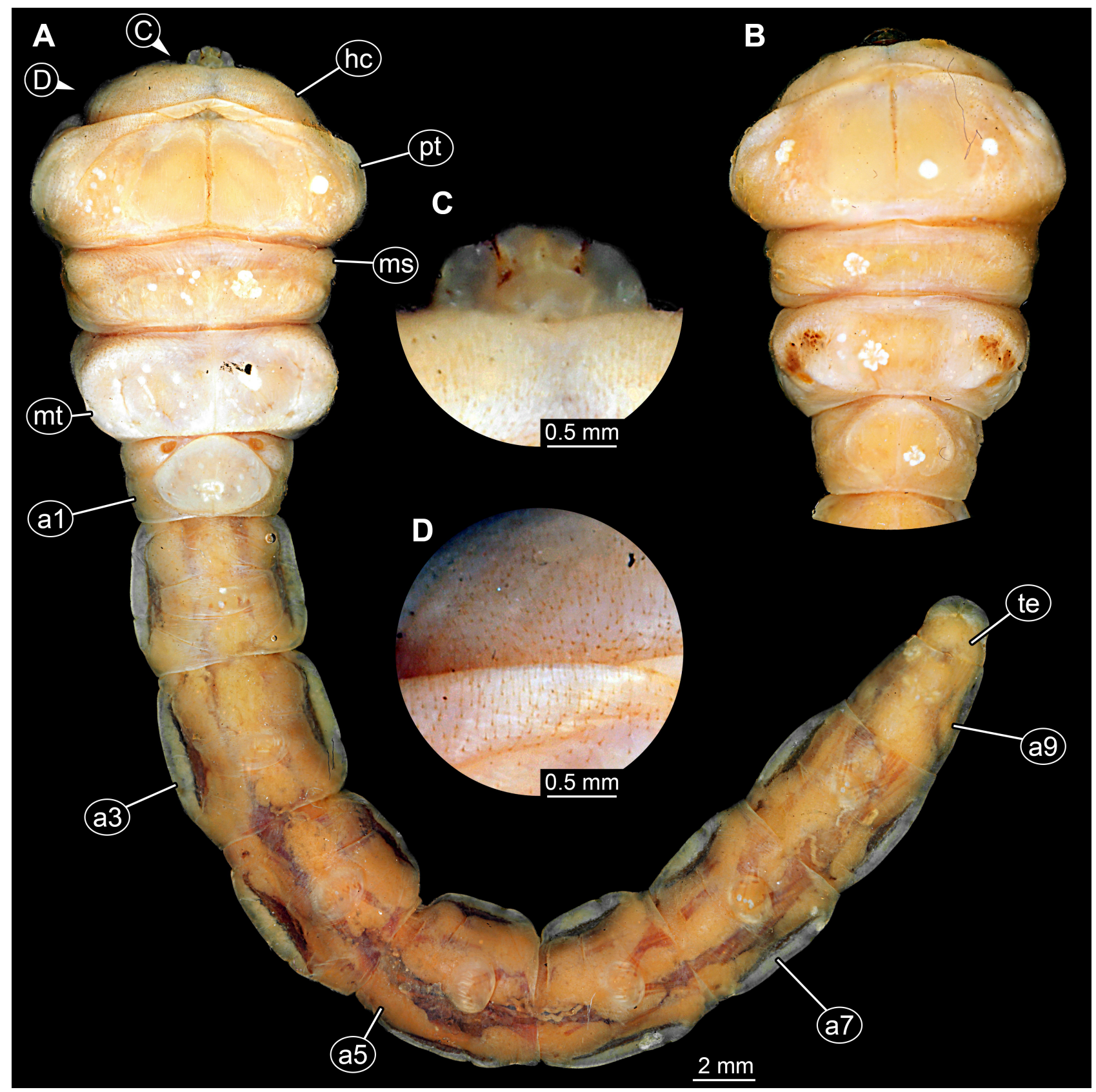

FIGURE 2. Extant larva of Buprestidae; ZMH 62921. A, Ventral view. B, Dorsal view of anterior body. C, Detail of mouthparts. D, Detail of ventral region of thorax with numerous setae. Abbreviations: a1-a9 = abdomen segments 1-9; hc = head capsule; ms $=$ mesothorax $; \mathrm{mt}=$ metathorax $; \mathrm{pt}=$ prothorax $; \mathrm{te}=$ trunk end.

Abdomen units cylindrical, all approximately same in length, about $50 \%$ of prothorax length. Last two abdomen units narrower than the anterior abdomen segments. Long setae discernible on abdomen segments (length approximately same as width of segments). Setae position lateral, anterior or dorsal on the segment, exact chaetotaxy not reconstructible.

\section{PED 0838}

Larva preserved in probable dorsal view (Fig. 4A, B). Total body length $1.95 \mathrm{~mm}$. Head capsule trapezoid in dorsal view, strongly retracted into anterior trunk (prothorax). Visible part of head capsule about 3.4 times wider than long. No antennae discernible. Mouth parts partly accessible (probable mandible and palp) (Fig. 4C).

Prothorax very prominent, roughly hexagonal in dorsal view ( $0.31 \mathrm{~mm}$ long and $0.43 \mathrm{~mm}$ wide); almost 6 times longer than visible part of head, also about 2.5 times wider. Middle part of prothorax widest, about 1.4 times wider than long. Pronotum set-off, divided by longitudinal line. Meso- and metathorax similar in width to posterior width of prothorax; shorter than prothorax, each only $30 \%$ of prothorax length. No locomotory appendages (legs) discernible. 


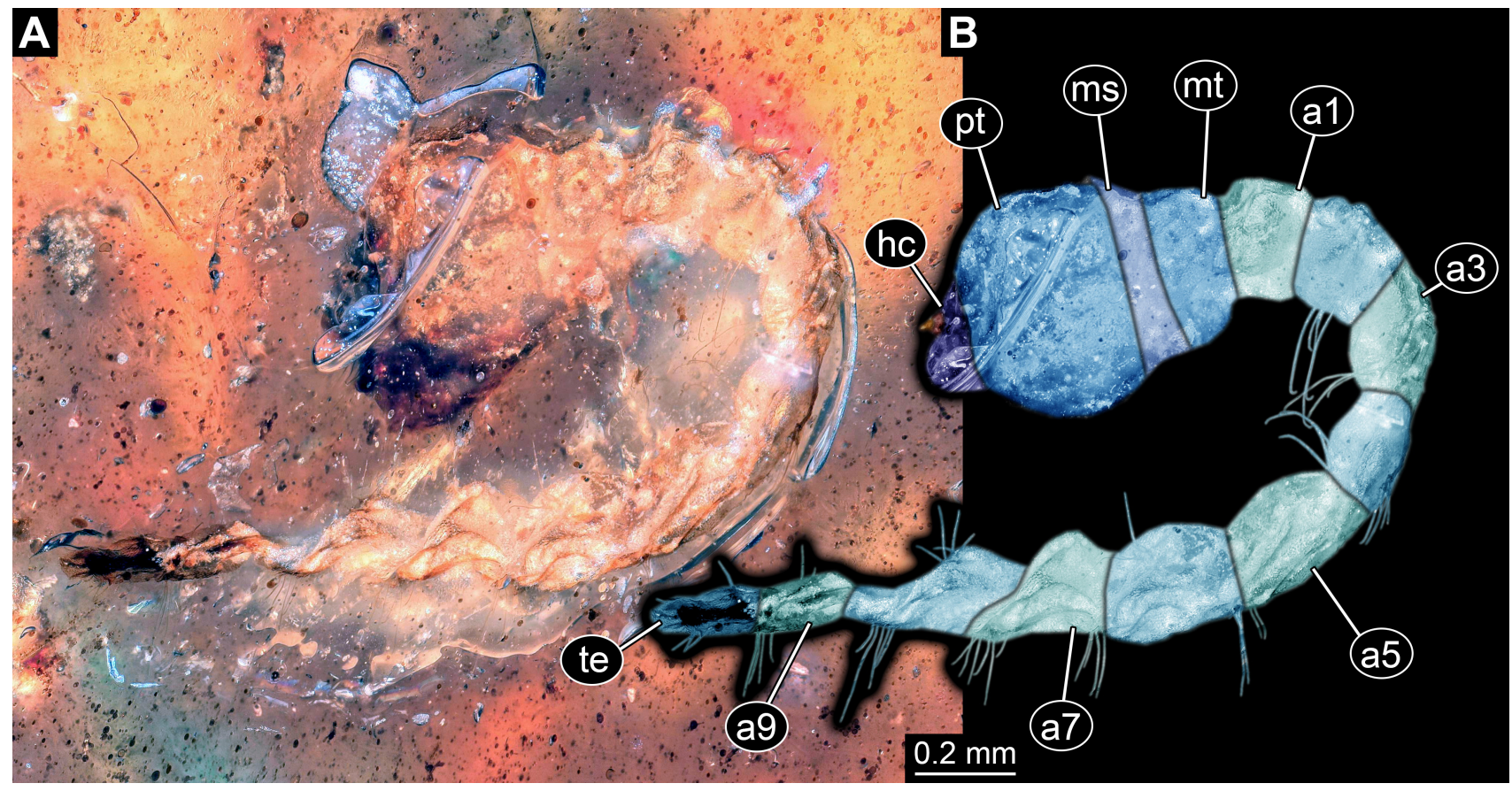

FIGURE 3. Fossil wood-borer larva without legs, Buprestidae, PED 0597. A, Dorsal or ventral view. B, Colour-marked version of A. Abbreviations: a1-a9 = abdomen segments $1-9$; hc $=$ head capsule; $\mathrm{ms}=$ mesothorax; $\mathrm{mt}=\operatorname{metathorax} ; \mathrm{pt}=\mathrm{prothorax}$; te $=$ trunk end.

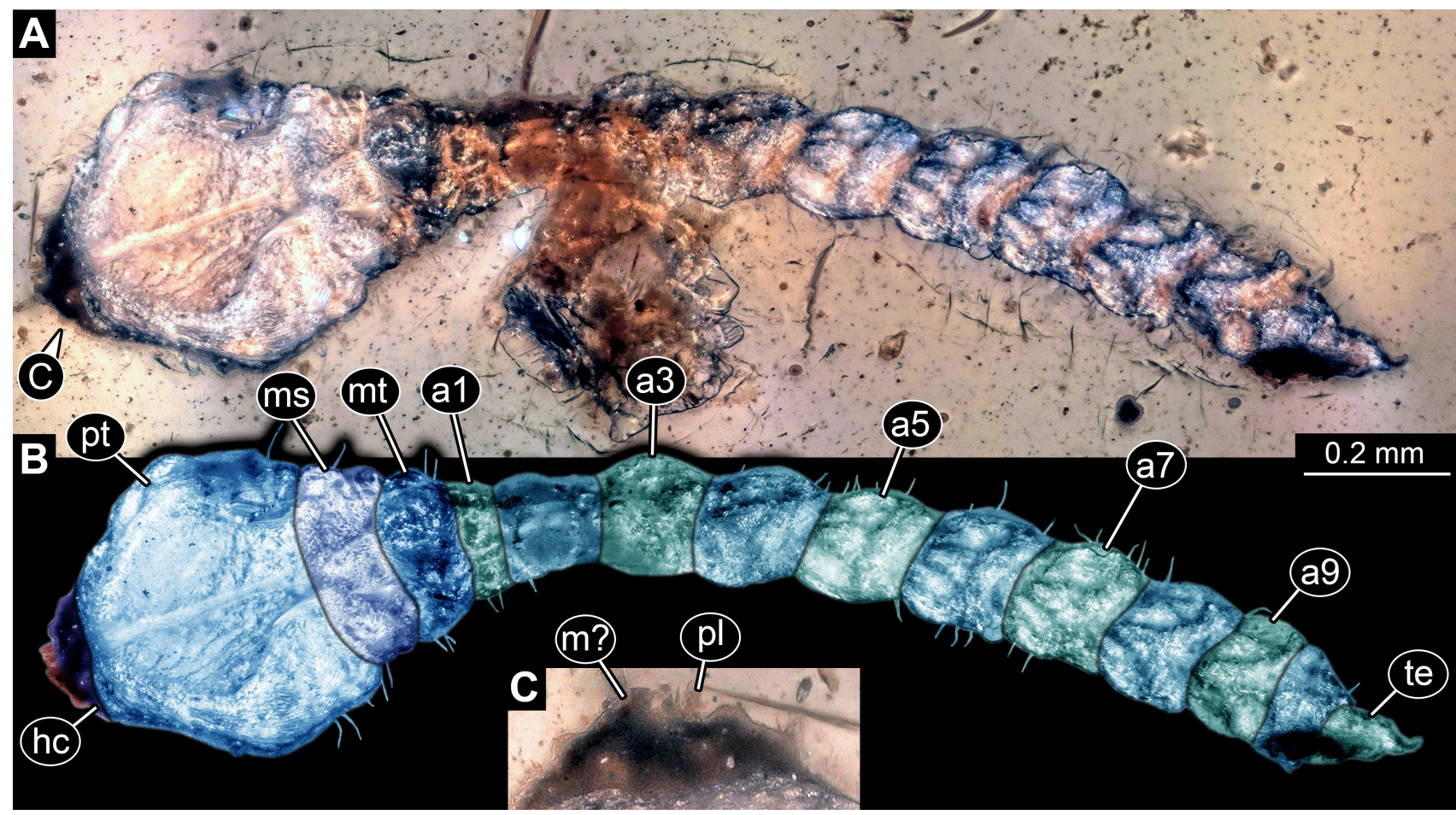

FIGURE 4. Fossil wood-borer larva without legs, Buprestidae, PED 0838. A, Dorsal (?) view. B, Colour-marked version of A. C, Details of mouthparts. Abbreviations: a1-a9 = abdomen segments $1-9$; hc $=$ head capsule; $\mathrm{m}$ ? = possible mandible; $\mathrm{ms}=$ mesothorax; $\mathrm{mt}=$ metathorax; $\mathrm{pl}=\mathrm{palp} ; \mathrm{pt}=$ prothorax.

Abdomen units cylindrical. Abdomen segment 1 shortest, about $20 \%$ of prothorax length; about $30 \%$ narrower than prothorax width. Remaining abdomen units similar in width, but about 2.5 times longer than abdomen segment 1 . Terminal end triangular in dorsal view. Lateral sides of thorax and abdomen segments with short setae.
PED 0816

Larva preserved in dorsal view (Fig. 5A, B). Total body length $2.24 \mathrm{~mm}$. Head capsule trapezoid in dorsal view. Head capsule wider than long, 2.7 times. Three stemmata discernible antero-laterally on both sides (Fig. 5D). No 


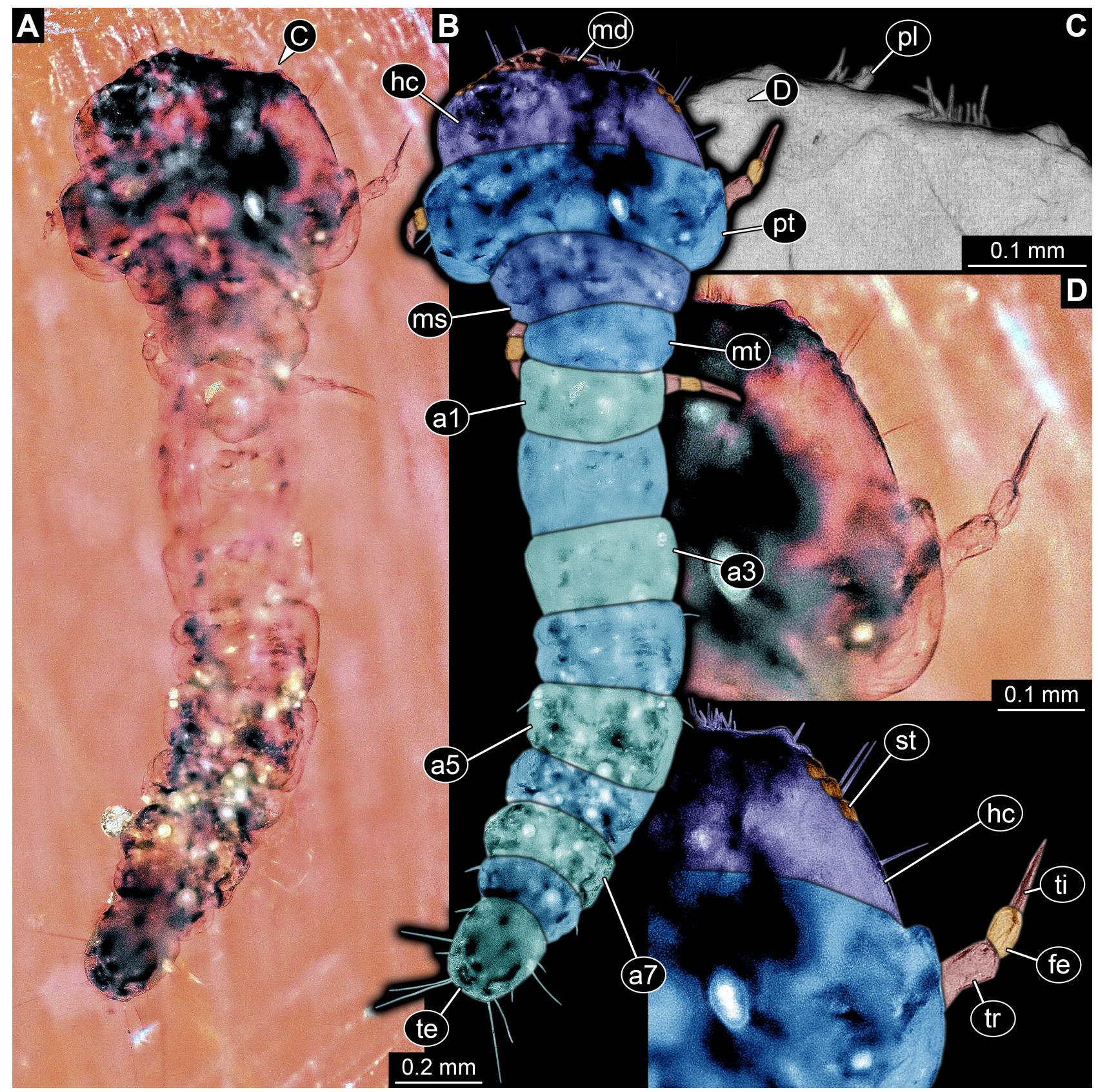

FIGURE 5. Fossil wood-borer larva with legs, Cerambycidae?/Buprestidae?, PED 0816. A, Dorsal view. B, Colour-marked version of A. C, Detail of anterior head region (image processed according to Haug et al., 2009). D, Upper part: detail of anterior body region; lower part: colour-marked version of upper part. Abbreviations: a1-a7 = abdomen segments $1-7$; fe $=$ femur; hc $=$ head capsule; $\mathrm{md}=$ mandible; $\mathrm{ms}=$ mesothorax; $\mathrm{mt}=$ metathorax; $\mathrm{pl}=$ palp; $\mathrm{pt}=$ prothorax; $\mathrm{st}=\mathrm{stemmata} ; \mathrm{t}=\mathrm{tibiotarsus} ; \mathrm{tr}=$ trochanter.

antennae discernible. Partial mouth parts discernible (prominent mandible and palp) (Fig. 5B, C).

Prothorax very prominent, ovoidal in shape from dorsal view ( $0.19 \mathrm{~mm}$ long and $0.68 \mathrm{~mm}$ wide). Prothorax 3.5 times wider than long. Slightly longer than head, also about 1.13 wider. Meso- and metathorax similar in width to posterior width of prothorax; only about $70 \%$ shorter than prothorax.

Thoracic segments with locomotory appendages legs. Three elements discernible: possible trochanter, femur, tibiotarsus (Fig. 5D). Abdomen units 1-8 similar in width and length to metathorax. Terminal end is ovoidal in dorsal view; 1.4 times longer than anterior abdominal segments, but only about $80 \%$ narrower.

Antero-lateral rim of the head capsule and lateral sides of prothorax and abdomen segments bear multiple setae. Terminal end bears distally and laterally two different types of setae; short setae similar to other setae; long setae about 4 times longer. 


\section{PED 1130}

Larva preserved in ventral view (Fig. 6A, B). Total body length $3 \mathrm{~mm}$. Head capsule trapezoid in ventral view. Head capsule 1.5 times wider than long. No antennae discernible. Partial mouth parts discernible (mandible, palp and possible labium) (Fig. 6B-D).

Prothorax quite prominent, ovoidal in dorsal view ( $0.57 \mathrm{~mm}$ long and $0.83 \mathrm{~mm}$ wide). Prothorax about 1.5 times wider than long; slightly longer and wider than head. Meso- and metathorax similar in width to posterior prothorax width. Mesothorax shorter, only about 25\% of prothorax length. Metathorax slightly longer. Thorax segments bear locomotory appendages (legs). Five elements discernible: coxa, trochanter, femur, tibia and claw-like tarsus (Fig. 6B).

Abdomen segments 1-4 similar in width and length, narrower and shorter than prothorax, only about $30 \%$ of length, only about $70 \%$ of width. Abdomen segments
5-7 similar in width to anterior abdomen segments but somewhat shorter, only about $25 \%$ of prothorax length. Abdomen units 8-10 narrower than further anterior segments, but as wide as abdomen segments $1-4$. Terminal end triangular in ventral view. Antero-lateral rim of the head capsule and lateral sides of thorax and abdomen segments bear multiple setae.

\section{Shape analysis}

In total, the data set contains 48 extant larvae ofBuprestidae, one extant larva of Schizopodidae, 29 extant larvae of Cerambycidae, six extant larvae of Eucnemidae, and the four new fossils described above. The analysis resulted in six effective principal components (Supplementary Fig. 1, Supplementary File 6). PC1 explains $46.3 \%$ of the overall variation, PC2 explains $21.0 \%$ of the overall variation (Supplementary File 6).

Plotting PC2 versus PC1 results in a large overlap

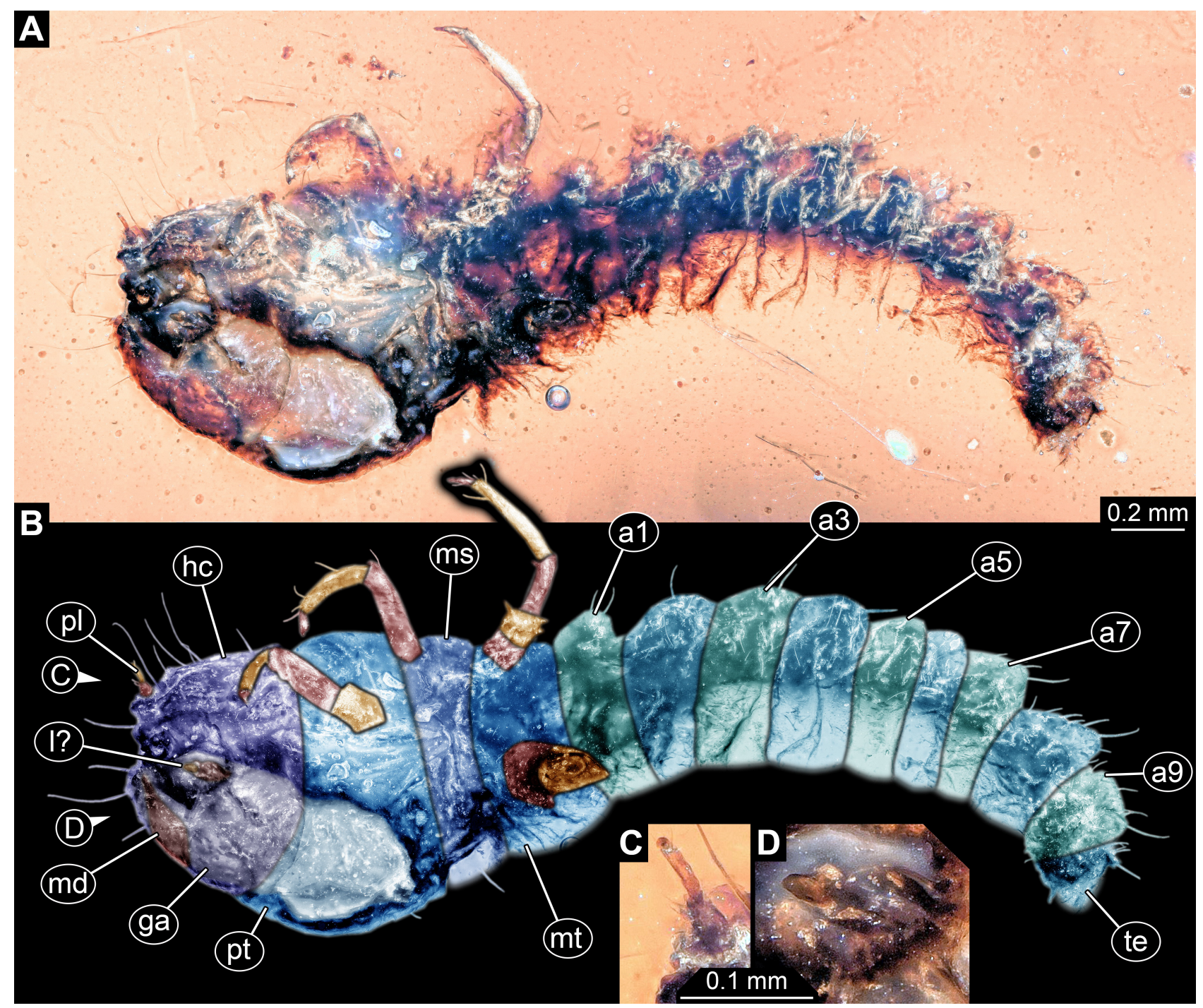

FIGURE 6. Fossil wood-borer larva with legs, Cerambycidae?/Buprestidae?, PED 1130. A, Ventral view. B, Colour-marked version of A. C, Detail of palp. D, Detail of remains of labium. Abbreviations: a1-a9 = abdomen segments $1-9$; ga $=$ groundoff area; $\mathrm{hc}=$ head capsule; 1 = possible remains of labium; $\mathrm{md}=$ mandible; $\mathrm{ms}=$ mesothorax; $\mathrm{mt}=$ metathorax; $\mathrm{pl}=\mathrm{palp} ; \mathrm{pt}=$ prothorax; te $=$ trunk end. 


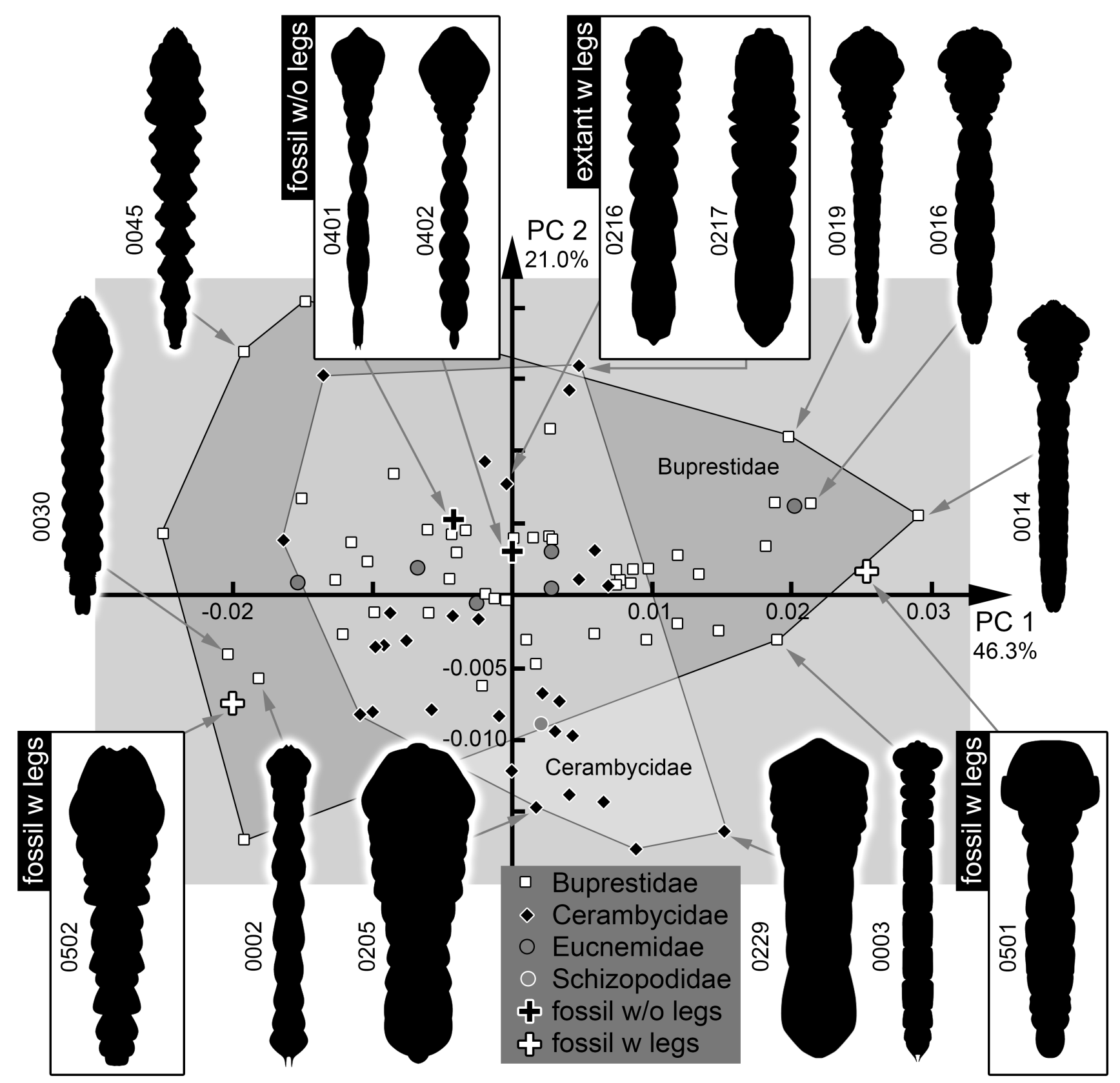

FIGURE 7. Morphospace, represented by principal component 2 (PC2) vs. principal component 1 (PC1) of the shape analysis of the body outline of wood-borer larvae. Numbers refer to the data set in Supplementary Tab. 1.

of the areas occupied by all groups (Fig. 7). The larvae of Eucnemidae plot entirely within the area occupied by those of Buprestidae. The two fossil larvae with legs plot relatively far away from the extant larvae with legs and also from each other. The two fossil larvae without legs plot quite close together and close to the centre of the morphospace.

When plotting the range of each effective PC for each group, the range is largest for Buprestidae for all PCs besides PC6 (Fig. 8). In most cases, the ranges of the other groups fall within those of Buprestidae.

\section{Discussion}

Fossil record of jewel beetles

The sister group of jewel beetles, Schizopodidae, is species-poor in the modern fauna, but already known since the Lower Cretaceous (Cai et al., 2015). The oldest fossil record of Buprestidae reaches back into the Middle Jurassic; older supposed fossils from the Triassic have been re-interpreted (Alexeev, 1999). Numerous adult specimens are known in Jurassic (Whalley \& Jarzembowski, 1985; Alekseev, 1993; Alexeev, 1999, 2000; Pan et al., 2011) and 


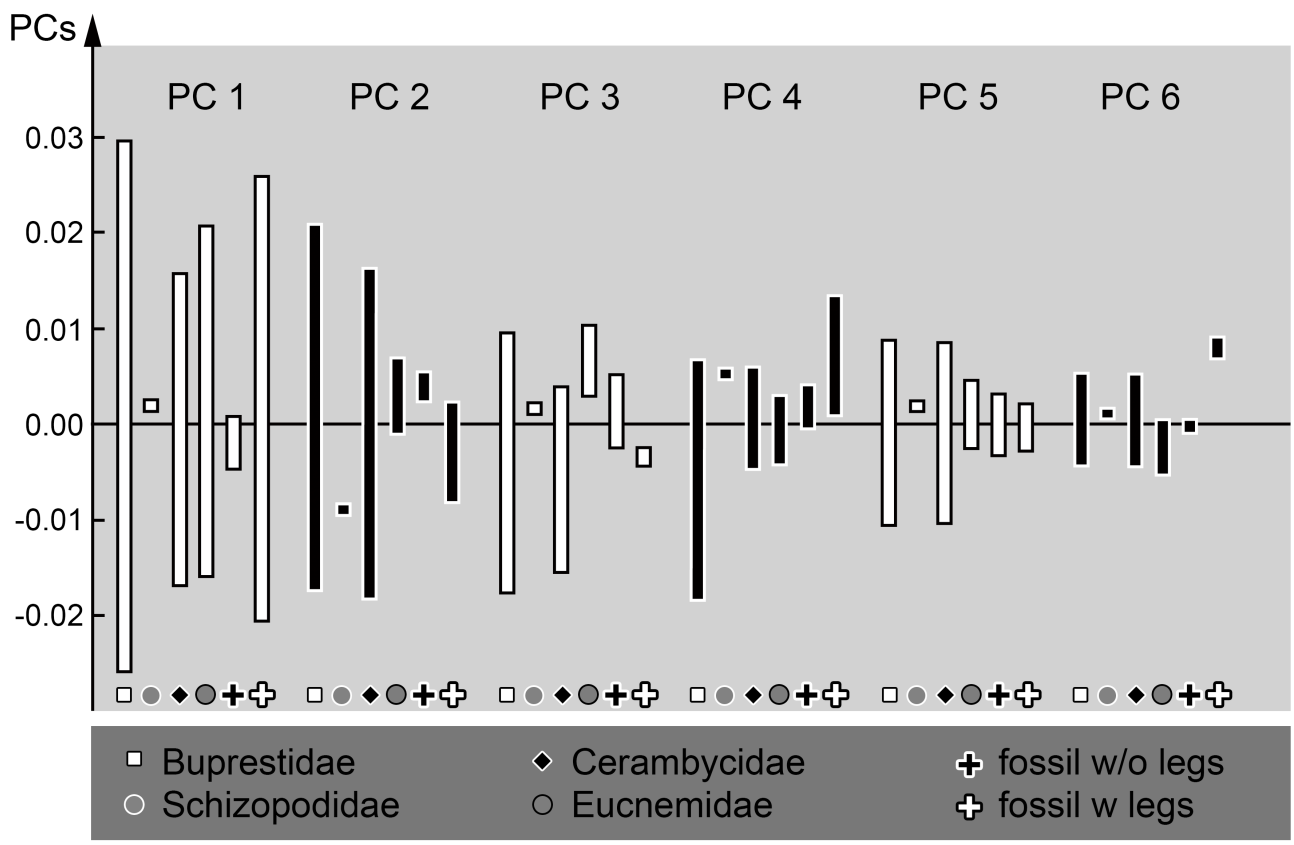

FIGURE 8. Ranges of all effective principal components (PCs) resulting from the shape analysis.

Cretaceous sedimentary rocks (Whalley \& Jarzembowski, 1985; Alekseev, 1993; Alexeev, 1999, 2000; MolinoOlmedo, 2011; Yu et al., 2013). Sedimentary rocks have also provided jewel beetle fossils in the Cenozoic (e.g., Ortuño \& Arillo, 2000; Simov et al., 2021). There are also some fossils in amber (e.g., Bellamy, 1999), but at least some of these seem to be challenging concerning their interpretation (Bellamy, 1995). Just recently, an adult jewel beetle has been reported from Kachin amber (Jiang et al., 2021; Ross, 2021).

One jewel beetle larva from Cretaceous New Jersey amber is known (Grimaldi \& Engel, 2005: 381, fig. 10.36) and some larvae in Eocene Baltic amber have been mentioned (Spahr, 1981 and references therein). In addition, leaf mining fossils from the Cretaceous have been interpreted as traces of jewel beetle larvae (Ding et al., 2014).

\section{Fossil record of longhorn beetles}

The group Cerambycidae occurs later in the fossil record than Buprestidae. The oldest fossil longhorn beetles have been reported from the Cretaceous (Wang et al., 2014; Yu et al., 2015), yet a fossil from the Late Jurassic has also been suggested to represent a longhorn beetle (Münster in Germar, 1839; see Vitali, 2019). Still, there is a time gap in comparison to jewel beetles. This time gap is, to a certain degree, congruent with reconstructions of dated phylogenies (McKenna et al., 2019), indicating an earlier diversification of jewel beetles.

Amber fossils are in fact quite numerous; yet so far only a single species has been recognised in Kachin amber,
Myanmar, namely Qitianniu zhihaoi Lin \& Bai, 2017 (Lin \& Bai, 2017; Vitali, 2019). Numerous specimens have been reported in Eocene amber (Vitali, 2005, 2009a, b, 2014, 2016; Alekseev \& Vitali, 2020), Miocene amber (Vitali, 2009b, c) and also non-fossil copal (Vitali, 2009b).

Some larvae in amber have been mentioned, but only few have been figured, and many seem now lost (Larsson, 1978; Vitali, 2009a: 235, 238). Some well preserved fossil larvae in Baltic amber have been figured in BachofenEcht (1949: 115, fig. 102) and Gröhn (2015: 272).

\section{Identity of the new fossil specimens}

In many cases, fossil larvae are rather challenging to interpret in a taxonomic or phylogenetic frame. In extant larvae, the focus in descriptions and documentation of morphological details is often on very specific characters that are considered crucial for taxonomy. However, these characters are not always visible in a fossil. While in extant larvae usually several specimens are available as basis for recognising characters of taxonomic value, the fossil larvae may be representatives of outgroups to the extant ones, hence such characters may not be informative. As a result, there can in fact be characters available in the fossil larvae for which no appropriate comparable frame is available. Therefore, only if the modern larvae are well known (including a certain variability in the respective group) and if morphological details are accessible in the fossils, it is possible to make a more educated guess or perform a strict analysis (for examples, see Badano et al., 2018, 2021). Yet, the shape of the larvae can also be informative to a certain extent by comparing it 
to the shape of their extant counterparts. In our case, important characters such as details of the mouthparts or chaetotaxy are not available in the fossil larvae; hence, a shape analysis was performed. In addition, qualitative morphological data were used for further identification where available.

Two of the new fossils presented here clearly lack legs and have a prominent broad prothorax, partly surrounding the broad head capsule; the abdomen is narrower, vermiform. All these aspects are highly compatible with an interpretation of these specimens as larvae of Buprestidae. Although there are some other holometabolan larvae with roughly comparable body shapes, e.g., leaf-mining caterpillars of the group Gracillariidae (e.g., Heppner, 1993: 53, fig. 10; Lopez-Vaamonde et al., 2021: 440, fig.17.1b), the overall morphology clearly is most similar to jewel beetle larvae.

This interpretation is further supported by the shape analysis, in which the fossil larvae plot within the area occupied by modern-day jewel beetle larvae. We therefore interpret these specimens as most likely the first report of jewel beetle larvae from Kachin amber, and also the oldest record of such larvae. Further identification within jewel beetles remains challenging, most details of mouthparts and seta arrangement are not accessible. Such further reaching interpretations will demand for better preserved specimens.

More problematic to understand are the other two fossils. They resemble the other larvae in having a broad prominent head with very prominent mandibles. Yet here the prothorax is even wider, partly embracing the head capsule, and also the abdomen is narrower.

The overall morphology of the two fossil larvae is therefore clearly compatible with an interpretation as a solid-wood borer. Solid-wood-boring larvae of Eucnemidae can easily be identified based on their outward-curving mandibles. Although many details are not accessible in the fossil larvae, their mandibles clearly are not outward curving, making an ingroup position in Eucnemidae unlikely.

In contrast to the two fossils interpreted as jewel beetles, the other two larvae possess prominent appendages on the thorax, commonly termed legs. All jewel beetle larvae lack legs. Only some larvae of longhorn beetles possess legs. Yet, these differ significantly in overall appearance from the two fossil larvae with legs. This is also further supported by the shape analysis. The two fossils plot outside the area occupied by larvae of Cerambycidae, closer to some larvae of Buprestidae, but also far away from each other. This makes the interpretation of these larvae more challenging.

It has been suggested that the presence of longer legs in modern longhorn beetle larvae, similar to those in the two fossils, is a novelty of a specific ingroup (Lepturinae;
Svacha \& Lawrence, 2014: 125). Given the difference in overall appearance, it seems unlikely that the two fossils are representatives of Lepturinae. Unfortunately, many details in the two larvae are not accessible. As many systematically important characters are not accessible in the fossils, we can only speculate to a certain degree. The fossils may represent larvae of early offshoots of either Cerambycidae or Buprestidae, which still retained longer legs. Even a clear decision between the two groups remains problematic as their overall appearance in the extant groups is a result of convergent evolution. Further, better preserved specimens will be necessary to further support or reject such an assumption. So far, we can only recognise that these two larvae are unusual types of wood borers. Although their overall body shape still plots within the range of modern-day wood borers, the combination with longer legs is not represented in the modern fauna, making these larvae another possible case of a now extinct morphology of holometabolan larvae found in Cretaceous ambers (e.g., Pérez-de la Fuente et al., 2012, 2016, 2018, 2019; Liu et al., 2016, 2018; Badano et al., 2018, 2021; Haug et al., 2019a-c, 2020a, b).

\section{Size of the fossils}

Extant wood-borer larvae can be quite large; the extreme within Buprestidae is over $100 \mathrm{~mm}$ (Bellamy \& Volkovitsh, 2005). Quite the contrary, the fossil larvae examined here are rather small; only a single modernday larva from the literature included in the data set is smaller than the fossils (Hernández \& de la Rosa, 2001). A similar observation has been made in the literature, for fossil larvae of the beetle group Scraptiidae preserved in amber, which are smaller than their modern counterparts (Haug \& Haug, 2019; Zippel et al., in review). So far, it cannot be easily excluded that this difference in size is caused by a taphonomic factor, i.e., that earlier stage larvae become more easily entombed in the still liquid resin than the larger later stages (see discussion in Haug \& Haug, 2019; Zippel et al., in review).

\section{The ecology and lifestyle of the fossil larvae}

As the new fossil larvae reported here resemble modernday solid-wood borers in many aspects, it is tempting to simply interpret them as solid-wood borers. Yet, there is a certain variability in the lifestyles of modern-day wood borers. For example, some smaller larvae may represent leaf miners (e.g., Grebennikov, 2013). As mentioned previously, leaf mines that could represent traces of jewel beetle larvae have already been recognised in Cretaceous leaves (Ding et al., 2014). Yet, the fossils reported here do not resemble leaf-mining larvae, which differ to a certain degree from the solid-wood-boring type larvae (Grebennikov, 2013). Hence, a leaf-mining lifestyle is unlikely, and the overall morphology is best compatible with an interpretation of the larvae as solid-wood borers. 
It is partly surprising to find solid-wood-boring and leaf-mining larvae in amber, as to become entrapped in amber they should be outside on the surface of a plant or on the ground, which such larvae usually do not do. Only very late-stage larvae will leave their host to pupate. The rather small size of the fossil larvae makes it unlikely that these are such late-stage larvae. Other possible leafmining larvae have been found in amber (see discussion in Haug \& Haug, 2021).

\section{Wood-borer larvae - a case of plant parasitism?}

Categorising the interaction between different organisms can be challenging. Often very distinct interactions are chosen as an example to specify a given category, instead of criteria. That makes the application to other cases sometimes very difficult. Also, for subcategories it is often difficult to remain in the same relational frame. For example, the terms "parasitic" and "free-living" are seen as opposites. Yet, these terms are in fact not in the same frame, "free-living" referring to an aspect of locomotion, "parasitic" potentially referring to aspects of feeding.

A more basic aspect is which types of organisms interact. Predation, for example, is most often used for an interaction of one metazoan with another metazoan. Yet, it has also been applied in other instances (e.g., seed predation; Janzen, 1971; Heithaus, 1981; Dylewski et al., 2020). Comparably, the term "parasitism" has also often been restricted to metazoan-metazoan interactions. Yet, for example for nematodes the term "plant parasitism" also seems widespread (Bongers et al., 1997; Kumar \& Yadav, 2020; Topalović et al., 2020). It has been discussed whether many more metazoan-plant interactions should in fact be categorised as cases of parasitism (Eggleton \& Gaston, 1990; Windsor, 1998; Poulin, 2011). This was especially emphasised for leaf-miners and other endophytic living organisms (Janzen, 1975; Price, 1980). This example applies also to larvae of Buprestidae, which are clearly not free-living (see above), but may even be considered parasites. Yet, the idea of parasitism of animals on (or within plants) seems not widely accepted (e.g., Labandeira \& Li, 2021).

So why is it interesting to think of wood-borer larvae as parasites? The larvae are highly specialised. In fact, they show specialisations that we could expect from clear endoparasites: loss of legs, overall vermiform body with specialised types of setae, e.g., for anchoring (Chiappini $\&$ Nicoli Aldini, 2011). As pointed out by Poulin (2011), it would clearly be beneficial to study such comparable cases beyond normal categories. It should be interesting to reconstruct the evolutionary path to endophytic life and to endoparasitic life.

The fossils reported here resemble their modernday counterparts to a high degree and do not contribute significantly towards such a reconstruction of character evolution. Yet, in a framework of palaeo-parasitism, such fossils should be considered, providing minimum ages for highly specialised morphologies (not reliably indirectly inferable; Baranov et al., 2019).

\section{Acknowledgements}

We thank two anonymous reviewers for helpful comments on the manuscript. JTH is funded by the Volkswagen Foundation with a Lichtenberg Professorship and by the German Research Foundation (DFG HA 6300/61). SVDW is funded by the Deutscher Akademischer Austauschdienst (DAAD; Research Grants-Doctoral Programmes in Germany, Reference no. 91693832). Fenja I. Haug, Neuried, is thanked for help with recording of images. The specimen from the CeNak Hamburg was documented during a student excursion in 2019; we therefore thank all students involved in the excursion, and the Lehre@LMU programme and the Faculty of Biology, LMU Munich, for financial support of the trip. Furthermore, we thank Martin Husemann and Thure Dalsgaard, both CeNak Hamburg, for providing access to the collections. J. Matthias Starck is thanked for longtime support. We thank all people providing free software. This is LEON publication \#28.

\section{References}

Alekseev, A.V. (1993) Jurassic and Lower Cretaceous Buprestidae (Coleoptera) from Eurasia. Paleontological Journal, 27 (1A), 9-34.

Alekseev, V.I. \& Vitali, F. (2020) Description of the first extinct member of the tribe Anaglyptini (Coleoptera: Cerambycidae) from European Tertiary. Zootaxa, 4816 (1), 135-143. https://doi.org/10.11646/zootaxa.4816.1.11

Alexeev, A.V. (1999) A survey of Mesozoic buprestids (Coleoptera) from Eurasian deposits. In: AMBA projects AM/PFICM98/1.99. Proceedings of the First International Palaeoentomological Conference, Moscow 1998, 5-9.

Alexeev, A.V. (2000) On Mesozoic Buprestids (Coleoptera: Buprestidae) from Russia, Kazakhstan, and Mongolia. Paleontological Journal C/C Of Paleontologicheskii Zhurnal, 34 (SUPP/3), S323-S326.

Bachofen-Echt, A. (1949) Der Bernsteine und seine Einschlüsse. Springer-Verlag, Wien, 204 pp. (reprint by Jörg Wunderlich Verlag 1996).

https://doi.org/10.1007/978-3-7091-2303-4

Badano, D., Engel, M.S., Basso, A., Wang, B. \& Cerretti, P. (2018) Diverse Cretaceous larvae reveal the evolutionary and behavioural history of antlions and lacewings. Nature Communications, 9, 3257. https://doi.org/10.1038/s41467-018-05484-y

Badano, D., Fratini, M., Maugeri, L., Palermo, F., Pieroni, N., Cedola, A., Haug, J.T., Weiterschan, T., Velten, J., Mei, M., Di Giulio, A. \& Cerretti, P. (2021) X-ray microtomography and phylogenomics provide insights into the morphology and 
evolution of an enigmatic Mesozoic insect larva. Systematic Entomology, 46, 672-684.

https://doi.org/10.1111/syen.12482

Baranov, V., Hoffeins, C., Hoffeins, H.-W. \& Haug, J.T. (2019) More than dead males: reconstructing the ontogenetic series of terrestrial non-biting midges from the Eocene amber forest. Bulletin of Geosciences, 94, 187-199.

https://doi.org/10.3140/bull.geosci.1739

Bellamy, C.L. (1995) Buprestidae (Coleoptera) from amber deposits: A brief review and family switch. The Coleopterists' Bulletin, 49, 175-177.

Bellamy, C.L. (1999) A new species of Buprestidae (Coleoptera) from Dominican amber. The Coleopterists' Bulletin, 53, 321323.

Bellamy, C.L. (2008-2009) A world catalogue and bibliography of the jewel beetles (Coleoptera: Buprestoidea). Pensoft Series Faunistica No. 76. Pensoft Publishers, Sofia, Moscow, 1-5, 3264 pp.

Bellamy, C.L. \& Volkovitsh, M.G. (2005) Chapter 17. Buprestoidea Crowson, 1955. In: Beutel, R.G. \& Leschen, R.A.B. (Eds), Handbuch der Zoologie/Handbook of Zoology, Volume IV, Arthropoda: Insecta, Part 38, Coleoptera, Beetles, Volume 1: Morphology and systematics. W. de Gruyter, Berlin, New York, pp. 461-468.

Bongers, T., van der Meulen, H. \& Korthals, G. (1997) Inverse relationship between the nematode maturity index and plant parasite index under enriched nutrient conditions. Applied Soil Ecology, 6 (2), 195-199.

https://doi.org/10.1016/S0929-1393(96)00136-9

Braig, F., Haug, J.T., Schädel, M. \& Haug, C. (2019) A new thylacocephalan crustacean from the Upper Jurassic lithographic limestones of southern Germany and the diversity of Thylacocephala. Palaeodiversity, 12, 69-87. https://doi.org/10.18476/pale.v12.a6

Cai, C.Y., Ślipiński, A. \& Huang, D.Y. (2015) First false jewel beetle (Coleoptera: Schizopodidae) from the Lower Cretaceous of China. Cretaceous Research, 52, 490-494.

https://doi.org/10.1016/j.cretres.2014.03.028

Chang, H.L., Muona, J., Pu, H.Y., Xu, L., Wang, C., Teräväinen, M., Ren, D., Yang, Q., Zhang, X.L. \& Jia, S.H. (2016) Chinese Cretaceous larva exposes a southern Californian living fossil (Insecta, Coleoptera, Eucnemidae). Cladistics, 32, 211-214. https://doi.org/10.1111/cla.12124

Chiappini, E. \& Nicoli Aldini, N. (2011) Morphological and physiological adaptations of wood-boring beetle larvae in timber. Journal of Entomological and Acarological Research, 43 (2), 47-59.

https://doi.org/10.4081/jear.2011.47

Connell, J., Hinterstoisser, W. \& Hoch, G. (2020) Notes on the larval morphology of Trichoferus campestris (Coleoptera, Cerambycidae), a wood borer frequently intercepted in wood packaging material. EPPO Bulletin, 50 (2), 316-321. https://doi.org/10.1111/epp.12668

Cruickshank, R.D. \& Ko, K. (2003) Geology of an amber locality in the Hukawng Valley, northern Myanmar. Journal of Asian Earth Sciences, 21, 441-455.

https://doi.org/10.1016/S1367-9120(02)00044-5
Ding, Q., Labandeira, C.C. \& Ren, D. (2014) Biology of a leaf miner (Coleoptera) on Liaoningocladus boii (Coniferales) from the Early Cretaceous of north-eastern China and the leafmining biology of possible insect culprit clades. Arthropod Systematics \& Phylogeny, 72, 281-308.

Dylewski, Ł., Ortega, Y.K., Bogdziewicz, M. \& Pearson, D.E. (2020) Seed size predicts global effects of small mammal seed predation on plant recruitment. Ecology Letters, 23 (6), 1024-1033.

https://doi.org/10.1111/ele.13499

Eggleton, P. \& Gaston, K.J. (1990) "Parasitoid" species and assemblages: Convenient definitions or misleading compromises? Oikos, 59, 417-421. https://doi.org/10.2307/3545155

Evans, H.F., Moraal, L.G. \& Pajares, J.A. (2007) Chapter 20. Biology, ecology and economic importance of Buprestidae and Cerambycidae. In: Lieutier, F., Day, K.R., Battisti, A., Grégoire, J.C. \& Evans, H.F (Eds), Bark and wood boring insects in living trees in Europe, a synthesis. Springer, Dordrecht, pp. 447-474.

https://doi.org/10.1007/1-4020-2241-7_20

Germar E.F. (1839) Die versteinerten Insecten Solenhofens. Nova Acta Physico-Medica Academiae Caesareae LeopoldinoCarolinae Naturae Curiosorum, 19 (1), 187-222.

Grebennikov, V.V. (2013) Life in two dimensions or keeping your head down: Lateral exuvial splits in leaf-mining larvae of Pachyschelus (Coleoptera: Buprestidae) and Cameraria (Lepidoptera: Gracillariidae). European Journal of Entomology, 110, 165-172.

https://doi.org/10.14411/eje.2013.024

Grimaldi, D. \& Engel, M.S. (2005) Evolution of the insects. Cambridge University Press, Cambridge, 755 pp.

Gröhn, C. (2015) Einschlüsse im baltischen Bernstein. Wachholtz Verlag, Kiel, 424 pp.

Haug, C., Mayer, G., Kutschera, V., Waloszek, D., Maas, A. \& Haug, J.T. (2011) Imaging and documenting gammarideans. International Journal of Zoology, 2011, art. 380829. https://doi.org/10.1155/2011/380829

Haug, C., Shannon, K.R., Nyborg, T. \& Vega, F.J. (2013) Isolated mantis shrimp dactyli from the Pliocene of North Carolina and their bearing on the history of Stomatopoda. Bolétin de la Sociedad Geológica Mexicana, 65, 273-284. https://doi.org/10.18268/BSGM2013v65n2a9

Haug, C., Herrera-Flórez, A.F., Müller, P. \& Haug, J.T. (2019a) Cretaceous chimera-an unusual 100-million-year old neuropteran larva from the "experimental phase" of insect evolution. Palaeodiversity, 12, 1-11. https://doi.org/10.18476/pale.v12.a1

Haug, G.T., Baranov, V., Wizen, G., Pazinato, P.G., Müller, P., Haug, C. \& Haug, J.T. (2021a) The morphological diversity of longnecked lacewing larvae (Neuroptera: Myrmeleontiformia). Bulletin of Geosciences, 96.

Haug, G.T., Haug, C. \& Haug J.T. (2021b) The morphological diversity of spoon-winged lacewing larvae and the first possible fossils from 99 million-year-old Kachin amber, Myanmar. Palaeodiversity, 14, 133-152. https://doi.org/10.18476/pale.v14.a6 
Haug, J.T. \& Haug, C. (2019) Beetle larvae with unusually large terminal ends and a fossil that beats them all (Scraptiidae, Coleoptera). PeerJ, 7, e7871.

https://doi.org/10.7717/peerj. 7871

Haug, J.T. \& Haug, C. (2021) A 100 million-year-old armoured caterpillar supports the early diversification of moths and butterflies. Gondwana Research, 93, 101-105. https://doi.org/10.1016/j.gr.2021.01.009

Haug, J.T., Haug, C. \& Ehrlich, M. (2008) First fossil stomatopod larva (Arthropoda: Crustacea) and a new way of documenting Solnhofen fossils (Upper Jurassic, Southern Germany). Palaeodiversity, 1, 103-109.

Haug, J.T., Haug, C., Maas, A., Fayers, S.R., Trewin, N.H. \& Waloszek, D. (2009) Simple 3D images from fossil and Recent micromaterial using light microscopy. Journal of Microscopy, $233,93-101$ https://doi.org/10.1111/j.1365-2818.2008.03100.x

Haug, J.T., Müller, P. \& Haug, C. (2019b) A 100-million-year old predator: a fossil neuropteran larva with unusually elongated mouthparts. Zoological Letters, 5, 29. https://doi.org/10.1186/s40851-019-0144-0

Haug, J.T., Müller, P. \& Haug, C. (2019c) A 100-million-year old slim insectan predator with massive venom-injecting styletsa new type of neuropteran larva from Burmese amber. Bulletin of Geosciences, 94, 431-440. https://doi.org/10.3140/bull.geosci.1753

Haug, J.T., Müller, P. \& Haug, C. (2020a) A 100 million-year-old snake-fly larva with an unusually large antenna. Bulletin of Geosciences, 95, 167-177. https://doi.org/10.3140/bull.geosci.1757

Haug, J.T., Schädel, M., Baranov, V.A. \& Haug, C. (2020b) An unusual 100-million-year old holometabolan larva with a piercing mouth cone. PeerJ, 8, e8661. https://doi.org/10.7717/peerj.8661

Heithaus, E.R. (1981) Seed predation by rodents on three antdispersed plants. Ecology, 62(1), 136-145. https://doi.org/10.2307/1936677

Heppner, J.B. (1993) Citrus leafminer, Phyllocnistis citrella, in Florida (Lepidoptera: Gracillariidae: Phyllocnistinae). Tropical Lepidoptera, 4, 49-64.

Hernández, J.M. \& de la Rosa, J.J. (2001) Description of larva and pupa of Plagionotus scalaris (Brullé, 1832) and distinctive host plant for Central Spain populations (Coleoptera, Cerambycidae, Cerambycinae). Deutsche Entomologische Zeitschrift, 48 (2), 267-271.

https://doi.org/10.1002/mmnd.4800480204

Hörnschemeyer, T. (2016) 5.3 Micromalthidae, Barber, 1913. In: Beutel, R.G. \& Leschen, R.A.B. (Eds), Volume 1 Coleoptera, Beetles, Morphology and systematics, Handbook of Zoology. De Gruyter, Berlin, Boston, pp. 48-52.

Iwata, H. \& Ukai, Y. (2002) SHAPE: A computer program package for quantitative evaluation of biological shapes based on elliptic Fourier descriptors. Journal of Heredity, 93, 384-385. https://doi.org/10.1093/jhered/93.5.384

Janzen, D.H. (1971) Seed predation by animals. Annual Review of Ecology and Systematics, 2 (1), 465-492.

https://doi.org/10.1146/annurev.es.02.110171.002341
Janzen, D.H. (1975) Interactions of seeds and their insect predators/ parasitoids in a tropical deciduous forest. In Evolutionary strategies of parasitic insects and mites. Springer, Boston, MA. pp. 154-186.

https://doi.org/10.1007/978-1-4615-8732-3_8

Jiang, R., Song, H., Zhang, H. \& Wang, S. (2021) Burmagrilus cretacus gen. et sp. nov., the first Buprestidae from midCretaceous Burmese amber. Cretaceous Research, 125, 104866.

https://doi.org/10.1016/j.cretres.2021.104866

Kergoat, G.J., Meseguer, A.S. \& Jousselin, E. (2017) Evolution of plant-insect interactions: insights from macroevolutionary approaches in plants and herbivorous insects. Advances in Botanical Research, 81, 25-53. https://doi.org/10.1016/bs.abr.2016.09.005

Kerp, H. \& Bomfleur, B. (2011) Photography of plant fossilsnew techniques, old tricks. Review of Palaeobotany and Palynology, 166, 117-151.

https://doi.org/10.1016/j.revpalbo.2011.05.001

Kirejtshuk, A.G. \& Azar, D. (2008) New taxa of beetles (Insecta, Coleoptera) from Lebanese amber with evolutionary and systematic comments. Alavesia, 2, 15-46.

Kirkendall, L., Biedermann, P.H.W. \& Jordal, B. (2015) Chapter 3: Evolution and diversity of bark and ambrosia beetles. In: Vega, F.E. \& Hofstetter, R.W. (Eds), Bark beetles: biology and ecology of native and invasivesSpecies. Academic Press, Cambridge. pp. 85-156. https://doi.org/10.1016/B978-0-12-417156-5.00003-4

Kumar, Y. \& Yadav, B.C. (2020) Plant-parasitic nematodes: Nature's most successful plant parasite. International Journal of Research and Review, 7, 379-386.

Labandeira, C.C. \& Li, L. (2021) The history of insect parasitism and the Mid-Mesozoic parasitoid revolution. The evolution and fossil record of parasitism: Identification and macroevolution of parasites. Topics in Geobiology, 49, 377-533. https://doi.org/10.1007/978-3-030-42484-8_11

Larsson, S.G. (1978) Baltic amber: a palaeobiological study. Scandinavian Science Press, Klampenborg, Denmark, 192 pp.

Li, H., Chang, H., Muona, J., Zhao, Y. \& Ren, D. (2021) Subfamily Anischiinae (Coleoptera: Eucnemidae) in early Cretaceous of Northeast China. Insects, 12, 105. https://doi.org/10.3390/insects12020105

Lin, M.Y. \& Bai, M. (2017) Qitianniu zhihaoi gen. et sp. nov.: The first cerambycid beetle found in Cretaceous Burmese amber (Coleoptera: Chrysomeloidea). Cretaceous Research, 75, 173-178.

https://doi.org/10.1016/j.cretres.2017.03.030

Liu, X.Y., Zhang, W.W., Winterton, S.L., Breitkreuz, L.C.V. \& Engel, M.S. (2016) Early morphological specialization for insect-spider associations in Mesozoic lacewings. Current Biology, 26, 1590-1594.

https://doi.org/10.1016/j.cub.2016.04.039

Liu, X.Y., Shi, G.L., Xia, F.Y., Lu, X.M., Wang, B. \& Engel, M.S. (2018) Liverwort mimesis in a Cretaceous lacewing larva. Current Biology, 28, 1475-1481. https://doi.org/10.1016/j.cub.2018.03.060 
Lopez-Vaamonde, C., Kirichenko, N. \& Oshima, I. (2021) Chapter 17: Collecting, rearing, and preserving leaf-mining insects. In: Santos, J.C. \& Fernandes, G.W. (Eds). Measuring arthropod biodiversity. Springer Nature Switzerland, Cham, pp. 439465. https://doi.org/10.1007/978-3-030-53226-0_17

McKenna, D.D., Shin, S., Ahrens, D., Balke, M., Beza-Beza, C., Clarke, D.J., Donath, A., Escalona, H.E., Friedrich, F., Letsch, H., Liu, S., Maddison, D., Mayer, C., Misof, B., Murin, P.J., Niehuis, O., Peters, R.S., Podsiadlowski, L., Pohl, H., Scully, E.D., Yan, E.V., Zhou, X., Ślipiński, A. \& Beutel, R.G. (2019) The evolution and genomic basis of beetle diversity. Proceedings of the National Academy of Sciences, 116, 24729-24737.

https://doi.org/10.1073/pnas.1909655116

Metcalf, R.L. (1996) Applied entomology in the twenty-first century. American Entomologist, 42, 216-227.

https://doi.org/10.1093/ae/42.4.216

Molino-Olmedo, F. (2011) Redescripción de la espèce fosíl Karatausia maculata Alekseev, 1993 (Coleoptera, Buprestidae). Lambillionea, 111, 1, 1-4.

Muona, J. (2010) Eucnemidae Eschscholtz, 1829. In: Leschen, R.A.B., Beutel, R.G., Lawrence, J.F. (Eds), Handbook of Zoology, Arthropoda: Insecta, Coleoptera, Beetles, Vol. 2: Morphology and Systematics (Elateroidea, Bostrichiformia, Cucujiformia partim). Walter de Gruyter, Berlin and New York, pp. 61-69.

https://doi.org/10.1515/9783110911213.61

Muona, J. \& Teräväinen, M. (2020) A re-evaluation of the Eucnemidae larval characters (Coleoptera). Papéis Avulsos de Zoologia, 60, art. e202060(s.i.).28.

https://doi.org/10.11606/1807-0205/2020.60.special-issue.28

Normark, B.B. (2013) Micromalthus debilis. Current Biology, 23, R430-R431.

https://doi.org/10.1016/j.cub.2013.02.045

Oberprieler, R.G., Ashman, L.G., Frese, M. \& Silipinìski, A. (2016) The first elateroid beetles (Coleoptera: Polyphaga: Elateroidea) from the Upper Jurassic of Australia. Zootaxa, 4147 (2), 177-191. https://doi.org/10.11646/zootaxa.4147.2.5

Oliveira, C.M., Auad, A.M., Mendes, S.M. \& Frizzas, M.R. (2014) Crop losses and the economic impact of insect pests on Brazilian agriculture. Crop Protection, 56, 50-54. https://doi.org/10.1016/j.cropro.2013.10.022

Ortuño, V.M. \& Arillo, A. (2000) Presencia del género Dicerca (Coleoptera, Buprestidae) en el Mioceno Superior de la depresión ceretana (Lleida, NE de España). Acta Geológica Hispánica, 35 (1), 189-193.

Pan, X., Chang, H., Ren, D. \& Shih, C. (2011) The first fossil buprestids from the Middle Jurassic Jiulongshan Formation of China (Coleoptera: Buprestidae). Zootaxa, 2745 (1), 53-62. https://doi.org/10.11646/zootaxa.2745.1.4

Pérez-de la Fuente, R., Delclòs, X., Peñalver, E., Speranza, M., Wierzchos, J., Ascaso, C. \& Engel, M.S. (2012) Early evolution and ecology of camouflage in insects. Proceedings of the National Academy of Sciences, 109, 21414-21419. https://doi.org/10.1073/pnas.1213775110
Pérez-de la Fuente, R., Delclòs, X., Peñalver, E. \& Engel, M.S. (2016) A defensive behavior and plant-insect interaction in Early Cretaceous amber - the case of the immature lacewing Hallucinochrysa diogenesi. Arthropod Structure and Development, 45, 133-139. https://doi.org/10.1016/j.asd.2015.08.002

Peìrez-de la Fuente, R., PenPalver, E., Azar, D. \& Engel, M.S. (2018) A soil-carrying lacewing larva in Early Cretaceous Lebanese amber. Scientific Reports, 8, art. 16663. https://doi.org/10.1038/s41598-018-34870-1

Pérez-de la Fuente, R., Engel, M.S., Azar, D. \& Peñalver, E. (2019) The hatching mechanism of 130-million-year-old insects: an association of neonates, egg shells and egg bursters in Lebanese amber. Palaeontology, 62, 547-559. https://doi.org/10.1111/pala.12414

Perotti, M.A., Young, D.K. \& Braig, H.R. (2016) The ghost sex-life of the paedogenetic beetle Micromalthus debilis. Scientific Reports, 6, art. 27364. https://doi.org/10.1038/srep27364

Peterson, A. (1957) Larvae of Insects. An Introduction to Nearctic Species. Part II. Coleoptera, Diptera, Neuroptera, Siphonaptera, Mecoptera, Trichoptera. Larvae of Insects. An Introduction to Nearctic Species. Edward Brothers, Columbus, $416 \mathrm{pp}$.

Pollock, D.A. \& Normark, B.B. (2002) The life cycle of Micromalthus debilis LeConte (1878)(Coleoptera: Archostemata: Micromalthidae): historical review and evolutionary perspective. Journal of Zoological Systematics and Evolutionary Research, 40, 105-112. https://doi.org/10.1046/j.1439-0469.2002.00183.x

Potts, S.G., Biesmeijer, J.C., Kremen, C., Neumann, P., Schweiger, O. \& Kunin, W.E. (2010) Global pollinator declines: trends, impacts and drivers. Trends in Ecology \& Evolution, 25, 345353.

https://doi.org/10.1016/j.tree.2010.01.007

Poulin, R. (2011) The many roads to parasitism: a tale of convergence. Advances in Parasitology, 74, 1-40. https://doi.org/10.1016/b978-0-12-385897-9.00001-x

Powney, G.D., Carvell, C., Edwards, M., Morris, R.K., Roy, H.E., Woodcock, B.A. \& Isaac, N.J. (2019) Widespread losses of pollinating insects in Britain. Nature Communications, 10, art. 1018. https://doi.org/10.1038/s41467-019-08974-9

Price, P.W. (1980) Evolutionary Biology of Parasites.(MPB-15), Volume 15. Princeton University Press, Princeton, $256 \mathrm{pp}$.

Prokhorov, A.V. \& Vasilyeva, J.S. (2017) Description of the Larva of Agrilus antiquus croaticus (Coleoptera, Buprestidae). Vestnik zoologii, 51 (1), 3-8. https://doi.org/10.1515/vzoo-2017-0001

Ross, A.J. (2021) Burmese (Myanmar) amber taxa, on-line supplement v.2021.1.27pp.

http://www.nms.ac.uk/explore/stories/natural-world/burmese-amber/

Schmidt, M., Liu, Y., Zhai, D., Hou, X. \& Melzer, R.R. (2021) Moving legs: A workflow on how to generate a flexible endopod of the 518 million-year-old Chengjiang arthropod Ercaicunia multinodosa using 3D-kinematics (Cambrian, 
China). Microscopy Research and Technique, 84, 695-704. https://doi.org/10.1002/jemt.23628

Shi, G., Grimaldi, D.A., Harlow, G.E., Wang, J., Wang, J., Yang, M., Lei, W., Li, Q. \& Li, X. (2012) Age constraint on Burmese amber based on $\mathrm{U}-\mathrm{Pb}$ dating of zircons. Cretaceous Research, 37, 155-163.

https://doi.org/10.1016/j.cretres.2012.03.014

Simov, N., Langourov, M., Sakalian, V. \& Bozukov, V. (2021) First fossil jewel beetle (Insecta: Coleoptera: Buprestidae) from Middle Miocene deposits in Bulgaria. Historia Naturalis Bulgarica, 42 (5), 31-34. https://doi.org/10.48027/hnb.42.052

Spahr, U. (1981) Bibliographie der Bernstein-und Kopal-Käfer (Coleoptera). Stuttgarter Beiträge zur Naturkunde, Serie B, 80, 1-107.

Svacha, P. \& Lawrence, J.F. (2014) 2.4. Cerambycidae Latreille, 1802. Volume 3. In: Leschen, R.A.B. \& Beutel, R.G. (Eds), Morphology and Systematics. De Gruyter, Berlin, München, Boston, 77-177 pp.

Swisher, C.C. III, Wang, Y.Q., Wang, X.L., Xu, X. \& Wang, Y. (1999) Cretaceous age for the feathered dinosaurs of Liaoning, China. Nature, 400, 58-61.

https://doi.org/10.1038/21872

Topalović, O., Hussain, M. \& Heuer, H. (2020) Plants and associated soil microbiota cooperatively suppress plantparasitic nematodes. Frontiers in Microbiology, 11, art. 313. https://doi.org/10.3389/fmicb.2020.00313

Vitali, F. (2005) Notes about the European fossil Lepturinae and the description of a new species (Coleoptera, Cerambycidae, Lepturinae). Lambillionea, CV, 4, 530-538.

Vitali, F. (2009a) The cerambycids included in Baltic amber: current knowledge status with the description of new taxa (Coleoptera, Cerambycidae). Denisia, 26, 231-242.

Vitali, F. (2009b) About some interesting fossil and subfossil cerambycids of the collection Velten (Coleoptera, Cerambycidae). Lambillionea, CIX, 352-357.

Vitali, F. (2009c) Two new longhorned beetles from Dominican amber (Coleoptera: Cerambycidae). Denisia, 26, 223-230.

Vitali,F.(2014)New fossil cerambycids (Coleoptera:Cerambycidae) from Baltic amber belonging to the collection Hoffeins. Baltic Journal of Coleopterology, 14 (1), 103-112.

Vitali, F. (2016) Eurapatophysis groehni n. gen. and n. sp. (Coleoptera: Cerambycidae) from Baltic amber: the first fossil member of the tribe Apatophyseini Lacordaire, 1869. Baltic Journal of Coleopterology, 16 (2), 117-122.

Vitali, F. (2019) Systematic notes on the Cerambycidae (Insecta: Coleoptera) described from Burmese amber. Palaeoentomology, 2 (3), 215-218.

https://doi.org/10.11646/palaeoentomology.2.3.3

Volkovitsh, M.G. \& Bílý, S. (2015) Larvae of Australian Buprestidae (Coleoptera). Part 5. Genera Astraeus and Xyroscelis, with notes on larval characters of Australian polycestine taxa. Acta Entomologica Musei Nationalis Pragae, 55, 173-202.

Wang, B., Ma, J., McKenna, D.D., Yan, E.V., Zhang, H. \& Jarzembowski, E.A. (2014) The earliest known longhorn beetle (Cerambycidae: Prioninae) and implications for the early evolution of Chrysomeloidea. Journal of Systematic Palaeontology, 12, 565-574.

https://doi.org/10.1080/14772019.2013.806602

Whalley, E.S. \& Jarzembowski, E.A. (1985) Fossil insects from the Lithographic Limestone of Montsech (late Jurassic-early Cretaceous), Lérida Province, Spain. Bulletin of the British Museum of Natural History (Geology), 38, 381-412. https://doi.org/10.5962/bhl.part.5051

Windsor, D.A. (1998) Controversies in parasitology: Most of the species on Earth are parasites. International Journal for Parasitology, 28, 1939-1941. https://doi.org/10.1016/s0020-7519(98)00153-2

Wu, Y., Trepanowski, N.F., Molongoski, J.J., Reagel, P.F., Lingafelter, S.W., Nadel, H., Myers, S.W. \& Ray, A.M. (2017) Identification of wood-boring beetles (Cerambycidae and Buprestidae) intercepted in trade-associated solid wood packaging material using DNA barcoding and morphology. Scientific Reports, 7, art. 40316.

https://doi.org/10.1038/srep40316

Yu, T.T., Kelly, R., Mu, L., Ross, A., Kennedy, J., Broly, P., Xia, F.Y., Zhang, H.C., Wang, B. \& Dilcher, D. (2019) An ammonite trapped in Burmese amber. Proceedings of the National Academy of Sciences, 116, 11345-11350.

https://doi.org/10.1073/pnas.1821292116

Yu, Y.L., Ślipiński, A., Shih, C.K., Pang, H. \& Ren, D. (2013) A new fossil jewel beetle (Coleoptera: Buprestidae) from the Early Cretaceous of Inner Mongolia, China. Zootaxa, 3637 (3), 355-360.

https://doi.org/10.11646/zootaxa.3637.3.7

Yu, Y.L., Ślipiński, A., Reid, C., Shih, C.K., Pang, H. \& Ren, D. (2015) A new longhorn beetle (Coleoptera: Cerambycidae) from the Early Cretaceous Jehol Biota of western Liaoning in China. Cretaceous Research, 52, 453-460. https://doi.org/10.1016/j.cretres.2014.02.019

All Supplementary materials are available at: https://doi.org/10.11646/palaeoentomology.4.4.14

Supplementary material:

Supplementary Tab. 1. Sources of all specimens included in the shape analysis.

Supplementary Text 1. Additional references cited in Supplementary Table 1.

Supplementary Fig. 1. Graphical representation of the factor loadings of the shape analysis.

Supplementary Files 1-6. Files resulting from the shape analysis, including chain codes, aligned shapes, and principal component analysis. 